Jurnal Algoritme

Vol. 1, No. 1, Oktober 2020, Hal. $102-110$

\title{
Perbandingan Performa Algoritma Minimax Dan Alpha- Beta Pruning Pada Game Catur Cina
}

\author{
Marthin Hokuta Kurniawan ${ }^{1}$, Daniel Udjulawa ${ }^{2}$ \\ STMIK GI MDP; Jl. Rajawali No. 14 Palembang, Telp. (0711)376400 Fax/(0711)376360 \\ Jurusan Sistem Informasi, STMIK GI MDP, Palembang \\ e-mail: *1 marthinhokitakurniawan@gmail.com,,$\underline{2}$ daniel@mdp.ac.id
}

\begin{abstract}
Abstrak
Algoritma merupakan urutan yang lengkap dan logis, dengan urutan yang logis banyak cara yang dilakukan dengan urutan yang berbeda. Pada kasus ini akan dibandingkan performa dari algoritma Minimax dan Alpha Beta Pruning pada game Catur Cina (XiangQi). Tujuannnya adalah sejauh mana waktu yang digunakan oleh kedua algoritma tersebut efektif dalam permainan Catur Cina. Metodologi yang digunakan dalam membangun aplikasi adalah Rapid Application Development, yaitu merupakan pengembangan dari metodologi Software Development Life Cycle. Kegiatan yang dilakukan antara lain yaitu melakukan perencanaan dan analisis terhadap pengembangan game dan melakukan pembuatan game dengan menggunakan game engine Unity dan bahasa pemograman C\#, Editor yang digunakan adalah Atom. Hasil pembuatan game dan koding algoritma akan di uji coba dengan iterasi kedalaman dan preset yang ditentukan sesuai dengan Minimax dan Alpha-Beta Pruning. Data yang didapat yaitu kecepatan dan banyak putaran antara kedua algoritma. Data tersebut akan dibandingkan sehingga performa kedua algoritma akan terlihat jelas.
\end{abstract}

Kata kunci-Chinese Chess, Board Game, Unity, MiniMax, AlphaBeta

\begin{abstract}
Algorithm is a complete and logical sequence, with a logical order in many ways done in a different order. In this case, the performance of the Minimax and Alpha Beta Pruning algorithms will be compared in the Chinese Chess game (XiangQi). The aim is to what extent the time spent by the two algorithms is effective in Chinese chess. The methodology used in building the application is Rapid Application Development, which is a development of the Software Development Life Cycle methodology. Activities carried out include planning and analyzing game development and making games using the Unity game engine and the $C$ \# programming language. The editor used is Atom. The results of game creation and algorithm coding will be tested with iteration depths and presets determined according to Minimax and Alpha-Beta Pruning. The data obtained are the speed and number of turns between the two algorithms. The data will be compared so that the performance of the two algorithms will be clearly seen.
\end{abstract}

Keywords - Chinese Chess, Board Game, Unity, MiniMax, AlphaBeta. 


\section{PENDAHULUAN}

$G^{-}$ ame di dunia komputer sudah menjadi bagian dari perangkat lunak yang banyak digemari oleh pemakai komputer. Umumnya perkembangan sebuah komputer akan melalui perkembangan grafis yang terus mendorong kekuatan hardware grafik komputer maupun perkembangan Artificial Intelligence yang diterapkan pada game-game tersebut. Hal yang tidak dapat dilupakan pada game-game papan sederhana yang telah lama menjadi tempat kompetisi algoritma yang dituangkan dalam bentuk digital, Salah satunya adalah catur Xiangqi, game ini tidaklah berbeda dengan game papan lainya walaupun game ini lebih langka daripada Catur Internasional.

Jaman modern ini game papan masih diminati dikalangan anak muda. Game Papan adalah game yang biasanya terdiri dari papan dan berbagai jenis potongan (dadu, bidak, counter, dll.), sistem aturan, dan dua atau lebih pemain. Dengan adanya bantuan teknologi, game papan tersebut beralih menjadi game digital.

Game Digital adalah program interaktif untuk satu atau lebih pemain, yang merupakan adaptasi sistem game 'tradisional', dengan aturan, representasi pemain, dan lingkungan yang dikelola melalui badan elektronik, Karena keterbatasan teknologi, game digital terdahulu sangatlah jarang yang memiliki fitur multiplayer, maka diharuskan memiliki Artificial Intelligence atau yang disebut secara singkat dengan istilah " $A \Gamma$ '.[1]

Artificial Intelligence adalah serangkaian algoritma yang luas yang juga mencakup teknik dari teori kontrol, robotika, grafik komputer, dan ilmu komputer secara umum, AI pada game digital sering tidak merupakan " $A I$ " yang serupa pada penelitian ilmiah karena $A I$ pada game digital jarang memfasilitasi pembelajaran komputer atau kriteria standar lainnya, hanya merupakan perhitungan otomatis atau serangkaian respons yang telah ditentukan dengan bantuan Algoritma-algoritma tertentu.[2]

Algoritma adalah prosedur atau formula untuk menyelesaikan masalah berdasarkan apa yang konduktif pada urutan tindakan tertentu. Program komputer dapat dilihat sebagai gabungan berbagai algoritma yang rumit. Dalam matematika dan ilmu komputer, algoritma biasanya berarti prosedur kecil yang memecahkan masalah berulang-ulang. Salah satu Algoritma yang sering dipakai pada game papan digital ialah Algoritma Alpha-Beta Pruning.

Algoritma Alpha-Beta Pruning adalah teknik optimisasi untuk algoritma minimax agar dapat mengurangi waktu perhitungan dengan lebih cepat. Algoritma tersebut memungkinkan sistem bekerja ke level yang lebih dalam di pohon game dan memotong cabang di pohon game yang tidak perlu dicari karena sudah ada langkah yang lebih baik.[2]

Algoritma Alpha-Beta Pruning dan MiniMax merupakan algoritma AI yang paling sering digunakan dalam game-game berbentuk papan seperti catur karena algoritma menggunakan analisis node pohon dalam memecahkan masalah.

Xiangqi, atau Catur Cina, adalah game yang sangat populer di negara-negara Asia. Dipercayai bahwa baik Xiangqi maupun Catur Barat/International telah dikembangkan dari game Chaturanga asli India.

Bidak catur Cina biasanya berbentuk cakram datar, memiliki nama-nama yang mirip dengan yang digunakan dalam catur barat dan tertulis di atasnya huruf Cina. Selain raja dan dua menteri, masing-masing pemain mulai dengan dua benteng, dua kuda, dua gajah, dua meriam, dan lima bidak.[3]

Dengan pengertian singkat tersebut jelas bahwa Xiangqi adalah game papan yang berbeda dengan catur pada umumnya, yaitu memiliki peraturan gerak yang berbeda, buah yang berbeda dan papan yang berbeda. Hal-hal tersebut membutuhkan algoritma Alpha-Beta Pruning yang berbeda dari catur seperti pada umumnya.

Kurniawan, et., al (Perbandingan Performa Algoritma Minimax Dan Alpha-Beta Pruning Pada Game Catur Cina) 


\section{METODE PENELITIAN}

Dalam melakukan penelitian ini, metodologi yang digunakan yaitu metodologi iterasi (Iteration). Dan Rapid Application Development (RAD).[4] Metode Iterasi memiliki fase pengembangan, yaitu sebagai berikut:

\subsection{Tahapan Design}

Dalam tahap ini dilakukan Studi Literatur, Penulisan batas-batas skenario dan desain awal sistem.

\section{1.1 Studi Literatur}

Studi literatur dalam sebuah penelitian untuk mendapatkan gambaran yang menyeluruh tentang apa yang sudah dikerjakan orang lain dan bagaimana orang mengerjakannya, kemudian seberapa berbeda penelitian yang akan dilakukan. Studi literatur penting untuk menghindari usaha yang sebenarnya sudah pernah dilakukan orang lain. Dalam penelitian ini, penulis mencari dan mempelajari literatur-literatur berupa jurnal yang berkaitan dengan masalah yang diteliti.

\section{1.2 Penulisan Skenario}

Penelitian mensimulasikan keadaan tertentu pada papan catur, yang selebihnya di panggil "Skenario" sebanyak 10 skenario masing-masing dengan 5 kedalaman node untuk mengetahui performa algoritma pada game catur cina.

\section{1.3 Desain Sistem}

Pada fase ini dibuat rancangan bagaimana program bekerja sesuai dengan alat ukur pengujian.

\section{2 Tahapan Implementasi}

Dalam tahap ini dilakukan Development \& Demonstration terhadap algoritma serta program catur cina.

\section{2.1 Development}

Dalam tahap ini algoritma di implementasikan pada sistem agar program dapat berjalan sesuai dengan kebutuhan. Algoritma MiniMax dan Alpha-Beta Pruning diimplementasikan pada tahap ini.

\section{2.2 Refine \& Demonstrate}

Pada fase ini dilakukan pengujian program dan algoritma. Program yang telah dibuat diuji dengan tindakan seperti meletakkan bidak pada skenario, melakukan gerakan dan menjalankan algoritma tertentu serta memastikan semua gerakan bidak/pion sesuai dengan peraturan gerak game pada Federasi Catur Cina Internasional

Kurniawan, et., al (Perbandingan Performa Algoritma Minimax Dan Alpha-Beta Pruning

Pada Game Catur Cina) 


\section{3 Tahapan Playtest}

Pada fase ini penelitian melakukan analisis dan pengetesan hasil. Penulis membandingkan hasil performa dari kedua algoritma MiniMax dan Alpha-Beta Pruning berdasarkan kecepatan gerak, banyak node yang dilewati dan Win-to-Lose Ratio dengan mengukur skor menang dan kalah antara kedua sisi dengan algoritma yang berbeda

\section{4 Tahapan Evaluate}

Pada fase ini penelitian mengevaluasi hasil yang didapat dari fase Playtest dan membuat laporan.

\section{5 Spesifikasi Perangkat Keras dan Lunak}

Berikut ini adalah perangkat keras dan lunak yang digunakan selama ujicoba algoritma, diantaranya:

\subsubsection{Perangkat Keras}

1. Laptop ASUS X540LJ dengan Prosessor Intel ${ }^{\circledR}$ Core $^{\mathrm{TM}} \mathrm{i3}-4005 \mathrm{U}$ CPU @ $1.70 \mathrm{GHz}$ x64 dan Random Access Memory 4.00 GB.

2. Desktop PC dengan Intel ${ }^{\circledR}$ Core $^{\mathrm{TM}}$ i3-6100 CPU @ 3.70GHz x 64 dan Random Access Memory $8.00 \mathrm{~GB}$

\subsubsection{Perangkat Lunak}

\section{Sistem Operasi Microsoft Windows 10}

2. Game Engine Unity 2018.2.1f1 (64-bit).

3. Editor Program Atom

\subsection{Flowchart Game}

Untuk menggambarkan urutan-urutan proses pada system ini, maka digunakan sebuah flowchart sebagai penjelas. berikut ini adalah flowchart yang menggambarkan mulai game 


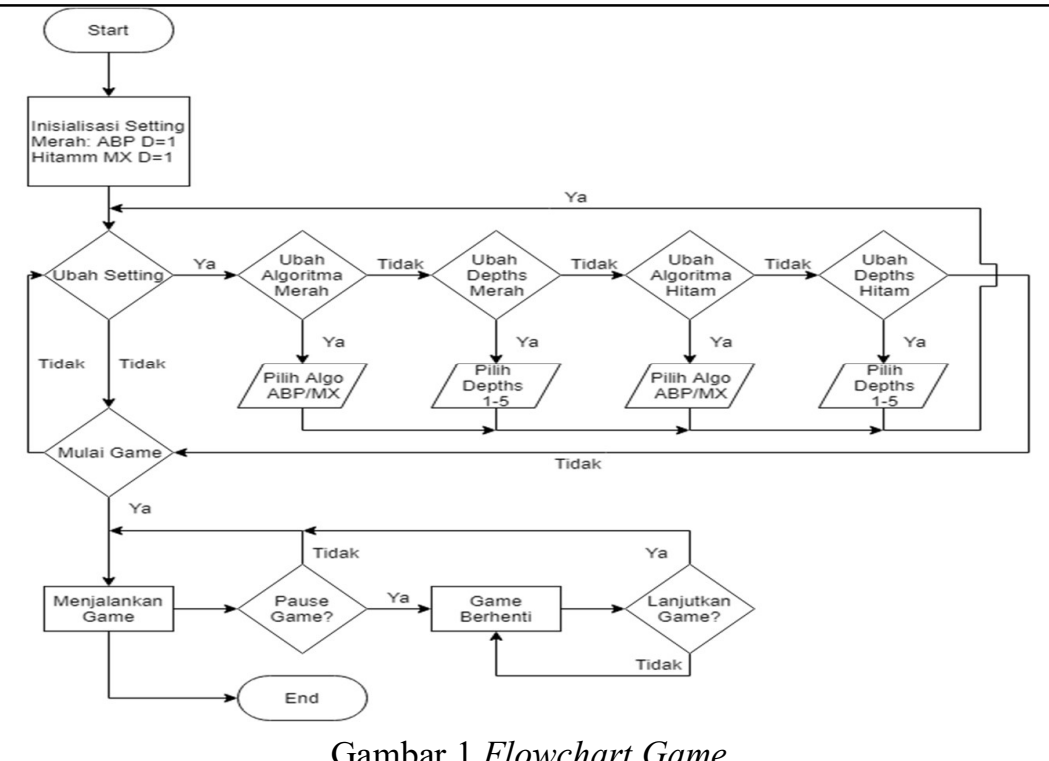

Gambar 1 Flowchart Game

\section{HASIL DAN PEMBAHASAN}

\subsection{Tampilan Game}

Berikut ini adalah tampilan game secara keseluruhan.

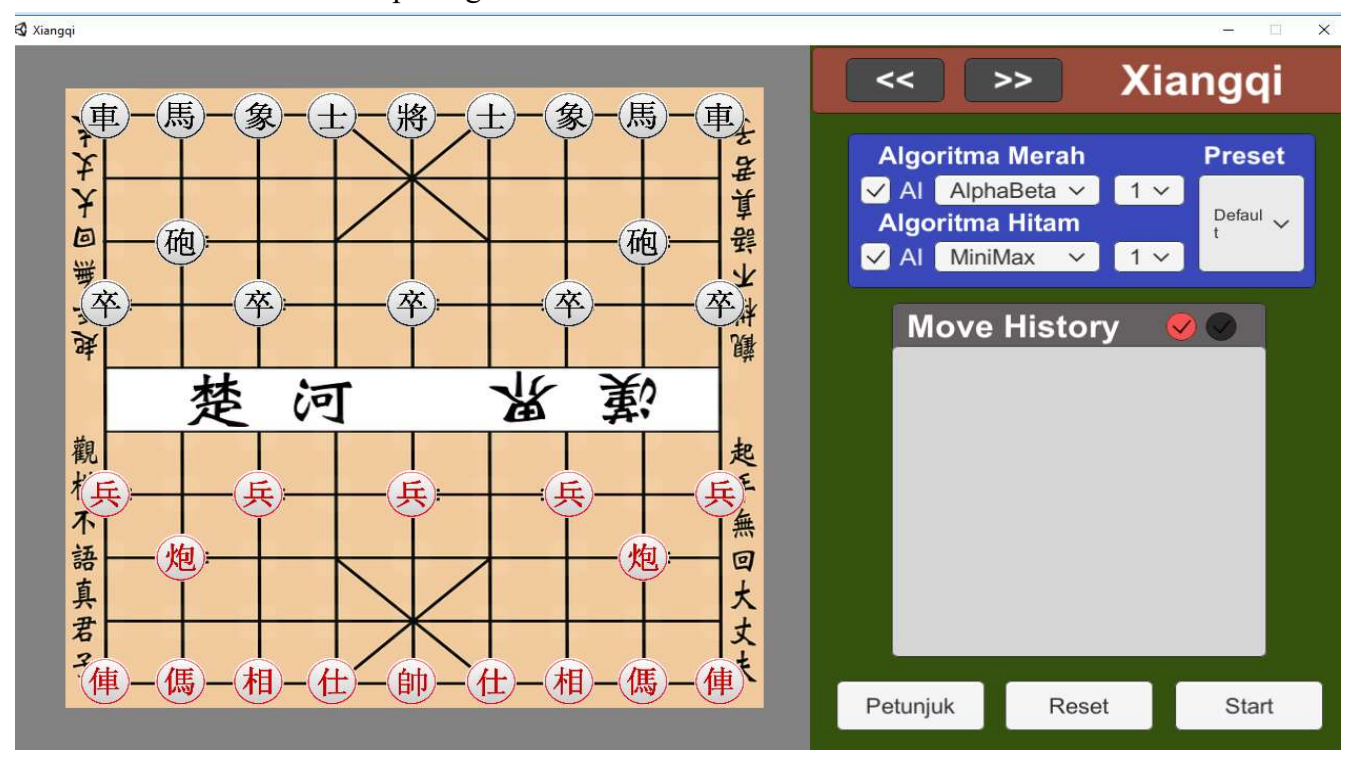

Gambar 2 Tampilan Game Catur Cina

\subsection{Tabel Hasil}

Dengan terkumpulnya data performa algoritma Minimax dan Alphabeta pada masing-masing Preset papan Xiangqi, maka tabel dapat disusun sesuai algoritma dan sisi papan, sehingga didapat hasil rata-rata pada kecepatan dan jumlah putaran.

Kurniawan, et., al (Perbandingan Performa Algoritma Minimax Dan Alpha-Beta Pruning Pada Game Catur Cina) 
Tabel 3.1 Rata-rata Minimax Sisi Hitam

\begin{tabular}{|c|c|c|c|c|c|}
\hline Black Minimax & 1 & 2 & 3 & 4 & 5 \\
\hline Default & 0.042 & 0.038 & 17.210 & 92.420 & \\
\hline Pawn Off The River A & 0.072 & 0.188 & 2.291 & 46.120 & \\
\hline Pawn Off The River B & 0.005 & 0.027 & 0.148 & 5.206 & \\
\hline Cannons Ommited & 0.006 & 0.099 & 1.037 & 10.113 & \\
\hline Flanking Cannons & 0.031 & 0.217 & 3.895 & 135.090 & \\
\hline Cannons and Forts & 0.017 & 0.310 & 7.385 & 55.260 & \\
\hline Knights and Elephants & 0.016 & 0.038 & 0.233 & 3.930 & \\
\hline Castle Siege A & 0.003 & 0.158 & 0.789 & 33.683 & \\
\hline Castle Siege B & 0.006 & 0.157 & 1.470 & 40.704 & \\
\hline Mirrored Advances & 0.013 & 0.330 & 3.301 & 59.070 & \\
\hline Average & 0.021 & 0.156 & 3.776 & 48.160 & \\
\hline
\end{tabular}

Tabel 3.2 Rata-rata Minimax Sisi Merah

\begin{tabular}{|c|c|c|c|c|c|}
\hline Red Minimax & 1 & 2 & 3 & 4 & 5 \\
\hline Default & 0.042 & 1.000 & 35.420 & 159.590 & \\
\hline Pawn Off The River A & 0.015 & 0.361 & 6.182 & 95.670 & \\
\hline Pawn Off The River B & 0.006 & 0.103 & 1.046 & 17.488 & \\
\hline Cannons Ommited & 0.006 & 0.103 & 1.369 & 8.661 & \\
\hline Flanking Cannons & 0.015 & 0.395 & 10.539 & 248.740 & \\
\hline Cannons and Forts & 0.025 & 0.422 & 9.403 & 54.010 & \\
\hline Knights and Elephants & 0.016 & 0.039 & 0.235 & 4.352 & \\
\hline Castle Siege A & 0.008 & 0.219 & 3.626 & 63.369 & \\
\hline Castle Siege B & 0.020 & 0.257 & 3.203 & 56.721 & \\
\hline Mirrored Advances & 0.014 & 0.536 & 4.394 & 69.270 & \\
\hline Average & 0.017 & 0.344 & 7.542 & 77.787 & \\
\hline
\end{tabular}

Tabel 3.3 Rata-rata AlphaBeta Sisi Hitam

\begin{tabular}{|c|c|c|c|c|c|}
\hline Black Alphabeta & 1 & 2 & 3 & 4 & 5 \\
\hline Default & 0.047 & 0.547 & 17.269 & 127.120 & \\
\hline Pawn Off The River A & 0.005 & 0.182 & 2.297 & 46.040 & \\
\hline Pawn Off The River B & 0.005 & 0.030 & 0.144 & 5.019 & \\
\hline Cannons Ommited & 0.003 & 0.102 & 1.503 & 9.140 & \\
\hline Flanking Cannons & 0.017 & 1.088 & 3.328 & 75.360 & \\
\hline Cannons and Forts & 0.011 & 0.166 & 7.762 & 64.840 & \\
\hline
\end{tabular}

Kurniawan, et., al (Perbandingan Performa Algoritma Minimax Dan Alpha-Beta Pruning Pada Game Catur Cina) 


\begin{tabular}{|c|c|c|c|c|c|}
\hline Knights and Elephants & 0.002 & 0.038 & 0.226 & 87.910 & \\
\hline Castle Siege A & 0.004 & 0.157 & 1.345 & 26.473 & \\
\hline Castle Siege B & 0.012 & 0.150 & 1.166 & 39.860 & \\
\hline Mirrored Advances & 0.032 & 0.152 & 3.394 & 79.870 & \\
\hline Average & 0.014 & 0.261 & 3.843 & 56.163 & \\
\hline
\end{tabular}

Tabel 3.4 Rata-rata AlphaBeta Sisi Merah

\begin{tabular}{|c|c|c|c|c|c|}
\hline Red Alphabeta & 1 & 2 & 3 & 4 & 5 \\
\hline Default & 0.045 & 0.732 & 17.747 & 190.600 & \\
\hline Pawn Off The River A & 0.012 & 0.357 & 6.169 & 95.850 & \\
\hline Pawn Off The River B & 0.011 & 0.069 & 0.756 & 21.427 & \\
\hline Cannons Ommited & 0.004 & 0.104 & 1.367 & 8.669 & \\
\hline Flanking Cannons & 0.015 & 0.404 & 10.699 & 219.190 & \\
\hline Cannons and Forts & 0.011 & 0.338 & 16.102 & 116.720 & \\
\hline Knights and Elephants & 0.004 & 0.050 & 0.327 & 5.695 & \\
\hline Castle Siege A & 0.007 & 0.212 & 4.054 & 54.880 & \\
\hline Castle Siege B & 0.023 & 0.344 & 3.060 & 55.070 & \\
\hline Mirrored Advances & 0.056 & 0.377 & 4.660 & 57.140 & \\
\hline Average & 0.019 & 0.299 & 6.494 & 82.524 & \\
\hline
\end{tabular}

Tabel 3.5 Rata-rata Putaran Minimax

\begin{tabular}{|c|c|c|c|c|}
\hline Turns Minimax & 1 & 2 & 3 & 4 \\
\hline Default & 19 & 10 & 9 & 7 \\
\hline Pawn Off The River A & 3 & 3 & 3 & 3 \\
\hline Pawn Off The River B & 3 & 3 & 3 & 10 \\
\hline Cannons Ommited & 7 & 7 & 7 & 7 \\
\hline Flanking Cannons & 9 & 4 & 4 & 5 \\
\hline Cannons and Forts & 9 & 5 & 4 & 2 \\
\hline Knights and Elephants & 5 & 5 & 4 & 5 \\
\hline Castle Siege A & 3 & 5 & 5 & 8 \\
\hline Castle Siege B & 9 & 8 & 7 & 19 \\
\hline Mirrored Advances & 5 & 4 & 3 & 3 \\
\hline Average & 7.2 & 5.4 & 4.9 & 6.9 \\
\hline
\end{tabular}

Tabel 3.6 Rata-rata Putaran AlphaBeta

\begin{tabular}{|c|c|c|c|c|}
\hline Turns Alphabeta & 1 & 2 & 3 & 4 \\
\hline Default & 18 & 10 & 9 & 10 \\
\hline
\end{tabular}

Kurniawan, et., al (Perbandingan Performa Algoritma Minimax Dan Alpha-Beta Pruning Pada Game Catur Cina) 


\begin{tabular}{|c|c|c|c|c|}
\cline { 1 - 1 } Pawn Off The River A & 3 & 3 & 3 & 3 \\
\hline Pawn Off The River B & 12 & 5 & 5 & 11 \\
\hline Cannons Ommited & 7 & 7 & 7 & 7 \\
\hline Flanking Cannons & 6 & 6 & 3 & 3 \\
\hline Cannons and Forts & 4 & 3 & 5 & 3 \\
\hline Knights and Elephants & 5 & 5 & 5 & 10 \\
\hline Castle Siege A & 5 & 7 & 8 & 6 \\
\hline Castle Siege B & 9 & 9 & 7 & 19 \\
\hline Mirrored Advances & 14 & 3 & 3 & 4 \\
\hline Average & 8.3 & 5.8 & 5.5 & 7.6 \\
\hline
\end{tabular}

Tabel 3.7 Rata-rata Kecepatan Algoritma

\begin{tabular}{|c|c|c|c|c|c|}
\hline Average & 1 & 2 & 3 & 4 & 5 \\
\hline Red MiniMax & 0.017 & 0.344 & 7.542 & 77.787 & \\
\hline Red Alphabeta & 0.019 & 0.299 & 6.494 & 82.524 & \\
\hline Black MiniMax & 0.021 & 0.156 & 3.776 & 48.160 & \\
\hline Black Alphabeta & 0.014 & 0.261 & 3.843 & 56.163 & \\
\hline
\end{tabular}

\section{KESIMPULAN}

Perbandingan Performa Alpha-Beta Pruning dan MiniMax pada Catur Cina (XiangQi) ini dimulai dengan perencanaan, desain dan implementasi, uji coba dan kemudian evaluasi. Dari proses-proses tersebut, penelitian ini memiliki kesimpulan sebagai berikut

1. Dapat dibuktikan bahwa algoritma Alpha-Beta Pruning tidak lebih cepat secara waktu atau efesien dalam banyak putaran dari algoritma MiniMax pada game catur cina (Xiangqi).

2. Perbedaan platform ujicoba yang dispesifikasikan di bab 3 dapat mempengaruhi kecepatan gerak algoritma, tetapi hasil yang didapat pada platform Laptop konsisten jika dibandingkan dengan hasil uji coba platform Desktop dengan rasio 2:1.

3. Suksesnya implementasi game Catur Cina (XiangQi) berbasis desktop dengan algoritma Alpha-Beta Pruning dan MiniMax serta 10 preset dan mode Player vs AI atau AI vs AI. 


\section{SARAN}

Dalam pengembangan dan perbandingan Alpha-Beta Pruning dan MiniMax pada Catur Cina (XiangQi) dapat disadari masih banyak kekurangan yang terdapat pada game serta penelitian yang telah dilakukan, Oleh sebab diharapkan penelitian ini dapat dikembangkan secara lebih lanjut. Saran penelitian ini yaitu :

1. Penelitian yang lebih lanjut mengenai E-value, yaitu bobot yang dimiliki setiap bidak sehingga algoritma dapat memproses gerakan bidak yang lebih pintar.

2. Penerapan atau pengembangan algoritma yang berbeda pada game Xiangqi agar mendapat AI yang lebih cepat dan efektif.

3. Penerapan pergerakan bidak serta logika koding yang lebih efisien, termasuk berbagai peraturan Xiangqi khusus dan pengecekan check dan checkmate yang sesuai.

\section{DAFTAR PUSTAKA}

[1] G.N. Yannakakis. 2012, Game AI Revisited. Center for Computer Games Research IT University of Copenhagen, Denmark.

[2] R. Stuart, N. Peter. 2018, Artificial Intelligence: A Modern Approach, Pertinence Hall. New Jersey.

[3] Yen, Shi-Jim Chen, JC Yang, TN Hsu, Shun-Chin, 2004, Computer Chinese Chess. ICGA journal. 27. 3-18. 10.3233/ICG-2004-27102. Taiwan.

[4] Hidayatullah, Priyanto, Jauhari Khairul Kawistara, 2014, Pemrograman WEB. Bandung : Informatika Bandung. (jQuery) 